\title{
Transversalidade entre Bourdieu e Fleck: campo e produção do conhecimento científico
}

\section{Transversality between Bourdieu and Fleck: field and production of scientific knowledge}

\author{
Yohana Taise Hoffmann* \\ David Antonio da Costa* \\ Ione Ribeiro Valle*
}

\begin{abstract}
RESUMO
Neste texto, o objetivo é apresentar duas visões a respeito do campo e a produção do conhecimento científico, à luz da epistemologia de Ludwik Fleck (1896-1961) e da sociologia de Pierre Bourdieu (1930-2002). Busca-se um diálogo e uma possível transversalidade, no sentido de que os autores se cruzam por determinados conceitos e ideias em relação ao modo de pensar o campo científico e sua produção de conhecimento, analisando aproximações e afastamentos. A aproximação entre esses autores é um exercício para olhar a produção da pesquisa e a construção de seu objeto, vislumbrando, em particular, a área da História da Educação Matemática (HEM) no Brasil. O artigo está dividido em duas partes. Na primeira, mobilizamos os aspectos epistemológicos que cada autor defende. Na segunda parte, focamos na constituição de um campo científico, como ocorre esse processo de instituição e quais são os movimentos e ações coletivas que fazem esse campo se fortalecer e compartilhar sua produção do conhecimento. Mobilizamos conceitos importantes para os autores, como estilo de pensamento e coletivo de pensamento para Fleck e campo científico e habitus para Bourdieu. A transversalidade entre os autores está relacionada principalmente ao co-
\end{abstract}

* Universidade Federal de Santa Catarina. Programa de Pós-Graduação em Educação Científica e Tecnológica. Florianópolis, Santa Catarina, Brasil. E-mail: yohana.thc@gmail.com. https:// orcid.org/0000-0002-3590-315X. E-mail: david.costa@ufsc.br. https://orcid.org/0000-0003-44939207. E-mail: ione.valle@ufsc.br. https://orcid.org/0000-0001-7496-3959. 
nhecimento científico, como algo social, que faz parte de um coletivo, e não isolado.

Palavras-chave: Campo científico. Epistemologia. Ludwik Fleck. Pierre Bourdieu. Sociologia.

\begin{abstract}
The aim of this paper is to present two approaches to the field and production of scientific knowledge, based on the epistemology of Ludwik Fleck (18961961) and sociology of Pierre Bourdieu (1930-2002). As the authors coincide in certain concepts and ideas regarding the way of thinking the scientific field and its knowledge production, we seek dialogue and a possible transversality, through the analysis of approximations and distances. The approximation of these authors is an exercise in looking at research production and the construction of its object, particularly when it comes to the History of Mathematics Education (HEM) in Brazil. This paper is comprised of two parts. First, we organize the epistemological aspects that each author defends. Then, we focus on the constitution of a scientific field, on the way this process of institution occurs, and on the movements and collective actions that strengthen this field and share its knowledge production. We list some important concepts for both authors, such as "thinking style" and "thought collective" for Fleck, as well as "scientific field" and "habitus" for Bourdieu. The transversality between these authors is mainly related to the conception of scientific knowledge as something social, part of a collective and not isolated.

Keywords: Scientific field. Epistemology. Ludwik Fleck. Pierre Bourdieu. Sociology.
\end{abstract}

\title{
Apresentação
}

A proposta neste artigo é colocar em diálogo dois autores de épocas, contextos e formação diferentes. É uma reflexão desafiadora na área da epistemologia, na teoria do conhecimento, e suas relações com a produção da pesquisa científica e com o campo científico, neste caso, em particular, temos como locus a área da História da Educação Matemática (HEM).

A partir da leitura dos autores mobilizados nas disciplinas ${ }^{1}$, respectivamente, Pierre Bourdieu (1930-2002) e Ludwik Fleck (1896-1961), buscou-se

1 Realização de duas disciplinas eletivas, na Universidade Federal de Santa Catarina, uma no Programa de Pós-Graduação em Educação, Dominação e Reprodução Social: a sociologia de 
colocar em diálogo dois modos de pensar o campo científico: o primeiro pela abordagem sociológica de Bourdieu (1989, 2001a, 2001b, 2004, 2013), o segundo pela abordagem epistemológica de Fleck (2010). Em ambos, buscou-se analisar aproximações e afastamentos de alguns conceitos e ideias em relação ao modo de pensar os elementos constitutivos de um campo científico e sua produção de conhecimento.

Bourdieu, filho único, nasceu em $1^{\circ}$ de agosto de 1930, em Denguin (França), e faleceu no dia 23 de janeiro de 2002, aos 71 anos, em Paris (França). Estudou no Liceu de Pau, frequentou em seguida o Liceu Louis Le Grand em Paris e, finalmente, a Escola Normal Superior. Sua formação filosófica tem como herança a história das ciências (tendo como referência Gaston Bachelard e George Canguilhem) e a fenomenologia (segundo a versão de Husserl e Merleau-Ponty), que entrou em crise no final dos anos 1950. Ele se distancia da filosofia para abordar um vasto campo das ciências sociais, de modo que produz uma teoria opondo-se, combinando, adaptando e retrabalhando os autores, conforme as necessidades concretas das análises sociais, a saber: Durkheim e Weber, Marx e Mauss, Cassirer e Wittgenstein, Husserl e Lévi-Strauss, Bachelard e Panofsky, por exemplo (VALLE, 2007).

Fleck, filho de judeus, nasceu em 11 de julho de 1896, na cidade de Lwöw (Ucrânia), e faleceu no dia 05 de junho de 1961, aos 65 anos, em Ness-Ziona (Israel). Fez medicina, sendo que, durante sua carreira profissional, suas investigações seguiram os estudos referentes à microbiologia (SCHÄFER; SCHNELLE, 2010). Desenvolveu trabalhos na área da epistemologia, generalizando suas proposições para além da medicina. Em seu livro Gênese e desenvolvimento de um fato científico (1935), valoriza

[...] o contexto histórico-psico-cultural ao analisar como se processa a introdução de um cientista numa nova forma de pensar, ou, como ele denomina, num novo "estilo de pensamento". Integra na sua análise, portanto, aspectos relativos à determinação social da investigação científica envolvidos no processo de produção de conhecimento (DELIZOICOV et al., 2002, p. 55).

No entanto, sabendo da trajetória de cada autor e atendo-se a perguntas que cada um buscou responder ao longo da sua vida acadêmica, não pretendemos

Pierre Bourdieu; e a outra no Ensino de Ciências e Sociogênese do Conhecimento, no Programa de Pós-Graduação em Educação Científica e Tecnológica. 
fazer comparações diretas e anacrônicas, mas levando em consideração suas ideias a respeito da produção do conhecimento científico. Buscamos um diálogo e uma possível transversalidade, no sentido de que os autores se cruzam por determinados conceitos em relação ao campo científico. A aproximação entre as ideias desses autores é um exercício para olhar a produção da pesquisa e a construção de seu objeto, vislumbrando, em particular, a área da HEM, buscando uma transversalidade entre essas concepções.

$\mathrm{O}$ texto estrutura-se em duas partes. Em um primeiro momento, mobilizamos os aspectos epistemológicos que cada autor defende, buscando realizar aproximações e distanciamentos, à luz da epistemologia fleckiana e da sociologia bourdieusiana. Na segunda parte, focamos nos aspectos relativos à constituição de um campo científico - como ocorre esse processo, quais são os movimentos e as ações coletivas compartilhadas que fortalecem e caracterizam esse espaço -, utilizando a HEM como lugar de investigação.

\section{Perspectivas epistemológicas: estruturalista construtivista e apriorista crítico}

Neste tópico apresentamos perspectivas epistemológicas dos autores, Bourdieu e Fleck, buscando uma transversalidade, atentando para não fazermos anacronismos, pois os autores são de épocas, contextos e áreas de formação diferentes. $\mathrm{Na}$ análise, observamos aproximações e distanciamentos dentro do processo de produção do conhecimento científico. Considera-se o posicionamento de Bourdieu como estruturalista construtivista

Bourdieu propõe o que chama de estruturalismo construtivista. Por estruturalismo, quer dizer que existe no mundo social, e não somente nos sistemas simbólicos, linguagens, mitos, estruturas objetivas, independentes da consciência ou da vontade dos agentes, capazes de orientar ou de impor suas práticas ou suas representações. Por construtivismo, entende que há uma gênese social tanto nos esquemas de percepção, de pensamento e de ação, quanto nas estruturas sociais (VALLE, 2007, p. 125).

E Fleck como apriorista crítico, pois, segundo o apriorismo, há em nosso conhecimento elementos que existem independentes da experiência, ou seja, são a priori. Por exemplo: 
A teoria comparada do conhecimento não deve considerar o processo do conhecimento como uma relação binária entre sujeito e objeto, entre o ator do conhecimento e algo a ser conhecido. O respectivo estado do saber, enquanto fator fundamental de cada conhecimento novo, deve entrar como o terceiro elemento nessa relação (FLECK, 2010, p. 81).

Já o criticismo, no sentido de que amanhã podemos conhecer ou saber mais que hoje, encontramos em diversos trechos da sua obra, uma delas: "o desenvolvimento do conceito da sífilis enquanto doença específica não é concluído, nem o pode ser [...] porém, surgiram também novos problemas e novos domínios do saber, de modo que, na verdade, nada está encerrado" (FLECK, 2010, p. 60).

A primeira aproximação entres os autores é a crítica ao positivismo instaurado na ciência. Fleck (2010, p. 95) menciona "se não conseguirmos saber 'tudo', de acordo com a velha receita, isso se deve simplesmente ao fato de o termo 'tudo' não fazer muito sentido em nosso contexto". A "velha receita" se refere ao positivismo, para ele a cada nova descoberta surge um novo problema, assim, os problemas são infinitos e o "tudo" não faz mais sentido. Já Bourdieu (2001a, p. 148) menciona que as ciências sociais poderiam assumir o racionalismo historicista ou um historicismo racionalista, "ainda que pareçam hoje fornecer suas melhores armas a uma denúncia irracionalista da ciência disfarçada em denúncia do cientificismo e do positivismo".

Segundo Valle (2008), Bourdieu buscou ultrapassar os dualismos, entre subjetivismo e objetivismo, estrutura e prática, pensamento e ação, trabalho empírico e análise conceitual. Nesse sentido, Bourdieu alerta para as possibilidades e os limites do conhecimento objetivo, da sua objetivação, ou seja, buscar as condições sociais e do sujeito no objeto construído pela ciência. Seria

[...] renunciar ao absolutismo do objetivismo clássico sem se condenar ao relativismo: de fato, a todo progresso no conhecimento das condições sociais de produção dos 'sujeitos' científicos corresponde um progresso no conhecimento do objeto científico, e vice-versa (BOURDIEU, 2001a, p. 146).

Bourdieu (1989) mostra "como" fazer pesquisa, como criar objetos e como relacionar as teorias e percepções intelectuais com os instrumentos de coleta e seus métodos. 
A fórmula inaugurada por Bourdieu exige do pesquisador certo desligamento ou distanciamento emocional do objeto e lhe impõe um importante desafio: separar as representações imediatas e os prejulgamentos espontâneos do saber científico. A eficiência dessa fórmula, que parte do princípio de que as práticas sociais resultam de uma cadeia complexa de ações (nem sempre conscientes) de longa duração, supõe primeiramente a revisão das categorias científicas mais habituais e dos recortes teórico-metodológicos mais tradicionais. Em seguida, a reaproximação de objetos diversos e de especializações disciplinares distintas (VALLE, 2007, p. 119).

Uma das reflexões mais importantes para a teoria de Bourdieu é pensar relacionalmente; ele aborda a tradição dominante de oposição entre teoria e metodologia. "Penso que se deve recusar completamente esta divisão em duas instâncias separadas, pois estou convencido de que não se pode reencontrar o concreto combinando duas abstrações" (BOURDIEU, 1989, p. 24). É importante que o pesquisador não tenha um pensamento segregador e isolador em relação à teoria e ao método e em relação ao contexto do objeto. Ele sustenta que "as opções técnicas mais 'empíricas' são inseparáveis das opções mais 'teóricas' de construção do objeto" (BOURDIEU, 1989, p. 24), o que também surge como contraponto à percepção cartesiana de fragmentação e separação.

O mesmo pensamento, em relação aos aspectos teóricos e práticos indissociáveis, amalgamados, podemos observar em Fleck (2010, p. 44), ao se referir aos "elementos teóricos e práticos, apriorísticos e puramente empíricos se interpenetraram - não segundo as regras da lógica, mas da psicologia: a empiria cedeu o lugar aos apriorismos emotivos".

Dessa maneira, podemos pensar a forma relacionar da utilização dos métodos como no exemplo de Bourdieu (1989, p. 26): "utilizar a análise das correspondências para fazer uma análise de discurso [...] ou combinar a mais clássica análise estatística com um conjunto de entrevistas em profundidade ou de observações etnográficas". Na percepção da construção do objeto, o pensar relacional está em pensá-lo dentro de seu contexto, “o objeto em questão não está isolado de um conjunto de relações de que retira o essencial das suas propriedades" (BOURDIEU, 1989, p. 27).

Segundo Fleck, corroborando Bourdieu nesse aspecto, o conhecimento não é isolado:

Aparecem novos motivos que o pensamento isolado e individual seria incapaz de gerar: propaganda, imitação, autoridade, concorrência, solidariedade, inimizade e amizade. Todos esses motivos ganham importância para 
a teoria do conhecimento, uma vez que todo o acervo de conhecimentos e a interação mental coletiva influenciam cada ato de conhecimento que, sem eles, seria, em princípio, impossível. Qualquer teoria do conhecimento que não leva em conta esse condicionamento social de todo conhecimento é uma brincadeira. Quem, entretanto, considera o condicionamento social como um mal necessário, como uma lamentável imperfeição humana a ser combatida, não sabe que, sem esse condicionamento, o conhecimento simplesmente não é possível, e - eu diria ainda - que a palavra "conhecer" somente ganha um significado no contexto de um coletivo de pensamento (FLECK, 2010, p. 86).

No conjunto da obra de Fleck (2010, p. 95), é possível observar seu criticismo no desenvolvimento da produção do conhecimento científico da mesma maneira que realiza a crítica ao "tudo", menciona que "não existe um 'último', algo fundamental que servisse de base para o conhecimento lógico". O processo de desenvolvimento da produção do conhecimento é o resultado sócio-histórico de um coletivo que está vinculado a fatores socioculturais, lógicos e empíricos. Dessa maneira, Fleck (2010, p. 82, grifo do autor) define coletivo de pensamento como uma

[...] comunidade das pessoas que trocam pensamentos ou se encontram numa situação de influência recíproca de pensamentos, temos, em cada uma dessas pessoas, um portador do desenvolvimento histórico de uma área de pensamento, de um determinado estado do saber e da cultura, ou seja, de um estilo específico de pensamento.

O coletivo de pensamento compreende uma comunidade que possui uma estrutura interna comum, uma tendência de união entre seus membros, que compartilham práticas, concepções, tradições e normas. Entretanto, "o coletivo de pensamento consiste em indivíduos diferentes, tendo também sua forma psíquica particular e regras particulares de comportamento" (FLECK, 2010, p. 87).

Por estilo de pensamento, entende-se como algo composto por ideias e práticas comuns partilhadas pelo coletivo, e que, em certa medida, condicionam e regulam a produção deste coletivo.

Podemos, portanto, definir o estilo de pensamento como percepção direcionada em conjunção com o processamento correspondente no plano 
mental e objetivo. Esse estilo é marcado por características comuns dos problemas, que interessam a um coletivo de pensamento; dos julgamentos, que considera como evidentes e dos métodos, que aplica como meios do conhecimento (FLECK, 2010, p. 149, grifo do autor).

No entanto, segundo Fleck (2010, p. 84), o coletivo de pensamento exerce uma força coercitiva no indivíduo, pois "o indivíduo nunca, ou quase nunca, está consciente do estilo de pensamento coletivo que, quase sempre, exerce uma força coercitiva em seu pensamento e contra a qual qualquer contradição é simplesmente impensável". Associando ao pensamento coercitivo, Bourdieu (2001a, p. 169) menciona que "o agente nunca é por inteiro o sujeito de suas práticas".

Podemos associar ainda, embora de maneira bastante genérica, o conceito de estilo de pensamento ao conceito de habitus para Bourdieu (2001a, p. 169, grifo do autor):

Uma das funções principais da noção de habitus consiste em descartar dois erros complementares cujo princípio é a visão escolástica: de um lado, o mecanismo segundo qual a ação constitui o efeito mecânico da coerção de causas externas; de outro, o finalismo segundo o qual, sobretudo por conta da teoria da ação racional, o agente atua de maneira livre, consciente e, como dizem alguns utilitaristas, with full understanding, sendo a ação o produto de um cálculo das chances e dos ganhos. Contra ambas as teorias, convém ressaltar que os agentes sociais são dotados de habitus, inscritos nos corpos pelas experiências passadas: tais sistemas de esquemas de percepção, apreciação e ação permitem tanto operar atos de conhecimento prático, fundados no mapeamento e no reconhecimento de estímulos condicionais e convencionais a que os agentes estão dispostos a reagir, como também engendrar, sem posição explícita de finalidades nem cálculo racional de meios, estratégias adaptadas e incessantemente renovadas, situadas porém nos limites das constrições estruturais de que são o produto e que as definem.

Em relação ao problema de pesquisa, segundo Bourdieu (1989, p. 28), os “objectos comuns da pesquisa são realidades que atraem a atenção do investigador por serem 'realidades que se tornam notadas' por assim dizer, a porém problemas". Assim como o estilo de pensamento, uma das características são os problemas comuns que interessam a um coletivo de pensamento.

Complementando com a perspectiva de Fleck (2010, p. 133) em relação à observação e à descoberta, o segredo está em fazer perguntas, em aprender 
a ver, "até o ponto de a resposta estar, na maioria dos casos, pré-formada na pergunta e em que basta decidir-se apenas por um sim ou não ou por uma constatação numérica, e até os métodos e aparelhos executarem a maior parte do pensamento para nós".

Para Bourdieu, Chamboredon e Passeron (1999, p. 64), saber construir e conhecer o objeto construído "é necessário ter consciência de que todo objeto propriamente científico é consciente e metodicamente construído, e é necessário conhecer tudo isso para nos interrogarmos sobre as técnicas de construção das perguntas formuladas ao objeto". Além disso, Bourdieu (1989, p. 41) menciona que

[...] os resultados não deixam de conferir uma espécie de diploma de objectividade ao sociólogo que soube dar uma realidade objectiva - pública - à representação subjectiva que eles têm do seu próprio ser social. [...] desde que vocês comecem a trabalhar num verdadeiro objecto construído, tudo se tornará difícil: o progresso "teórico" gera um acréscimo de dificuldades "metodológicas".

O objeto da pesquisa é fundamental na concepção de Bourdieu para não nos tornarmos objetos do próprio objeto: "deixar em estado impensado o seu próprio pensamento é, para um sociólogo mais ainda que para qualquer outro pensador, ficar condenado a ser apenas instrumento daquilo que ele quer pensar" (BOURDIEU, 1989, p. 36).

Para se não ser objeto dos problemas que se tomam para objeto, é preciso fazer a história social da emergência desses problemas, da sua constituição progressiva, quer dizer, do trabalho colectivo - frequentemente realizado na concorrência e na luta - o qual foi necessário para dar a conhecer e fazer reconhecer estes problemas como problemas legítimos, confessáveis, publicáveis, públicos, oficiais (BOURDIEU, 1989, p. 37).

A partir do excerto acima, podemos pensar relacionalmente com Fleck, em relação à formação do estilo de pensamento, ou seja, sua construção coletiva:

Qualquer conhecimento significa, em primeiro lugar: constatar, a partir de determinados pressupostos ativamente adotados, as relações que resultam 
de maneira coercitiva e passiva [...]. O estilo de pensamento não é apenas esse ou aquele matiz dos conceitos e essa ou aquela maneira de combiná-los. Ele é uma coerção definida de pensamento e mais: a totalidade das disposições mentais, a disposição para uma e não para outra maneira de perceber e agir. Evidencia-se a dependência do fato científico em relação ao estilo de pensamento (FLECK, 2010, p. 110).

Esse exercício, analisando as transversalidades entre as teorias de Bourdieu e Fleck, auxiliam para compreender a concepção de ciência e a construção do objeto a ser analisado dos autores. Dessa forma, podemos considerar que os autores se complementam, não são incongruentes. Assim, podemos referenciá-los ao tratar dos elementos constitutivos de um campo científico, utilizamos como locus a HEM, buscando caracterizar esse espaço à luz da epistemologia fleckiana e da sociologia bourdieusiana.

\section{História da Educação Matemática (HEM), um campo científico?}

Neste segundo momento, buscamos compreender os elementos constitutivos de um campo científico, a fim de compreender a sua estrutura, as estratégias e as relações que o compõem. Segundo Bourdieu (2001a, 2001b), o campo científico, assim como as demais instituições, é considerado como um espaço social, constituído por relações de força e de dominação, no qual os agentes estão dispostos de acordo com sua posição, isto é, entre dominantes ou dominados. O campo científico constitui-se em um espaço de lutas simbólicas. É um sistema constituído por relações objetivas entre posições adquiridas em lutas anteriores.

Os campos científicos, esses microcosmos que, sob certos aspectos, constituem mundos sociais idênticos aos demais, com concentrações de poder e de capital, monopólios, relações de força, interesses egoístas, conflitos etc., também constituem, sob outra perspectiva, universos de exceção, algo milagrosos, onde a necessidade da razão encontra-se instituída em graus diversos na realidade das estruturas e das disposições. [...] existem formas socialmente instituídas e garantidas de comunicação, como as que se impõem de fato no campo científico, conferindo plena eficácia a mecanismos de universalização como os controles mútuos impostos de modo mais eficaz pela lógica da concorrência do que todas as exortações à "imparcialidade" ou à "neutralidade ética" (BOURDIEU, 2001a, p. 133). 
O campo científico é um espaço de intensa competição entre os concorrentes do campo, por intensos conflitos, cujo objetivo é conservar ou transformar o mesmo. Assim, a primeira noção do campo científico, tal como nos demais campos, é de "um campo de forças dotado de uma estrutura e também um espaço de conflitos pela manutenção ou transformação desse campo de forças" (BOURDIEU, 2001b, p. 52). Um segundo momento da definição, como um "espaço de conflitos, como campo de ação socialmente construído em que os agentes dotados de diferentes recursos se defrontam para conservar ou transformar as relações de forças vigentes" (BOURDIEU, 2001b, p. 54).

Desta forma, o que está em jogo, em disputa, são os monopólios da autoridade científica. A ciência, segundo Bourdieu (2004, p. 21), precisa

[...] escapar à alternativa da "ciência pura", totalmente livre de qualquer necessidade social, e da "ciência escrava", sujeita a todas as demandas político-econômicas. O campo científico é o mundo social e, como tal, faz imposições, solicitações etc., que são, no entanto, relativamente independentes das pressões do mundo social global que o envolve.

Ou seja, para Bourdieu (2004, p. 30), o campo científico é um microcosmo que coloca em jogo o monopólio da autoridade científica: "Quanto mais os campos científicos são autônomos, mais eles escapam às leis sociais externas”. Porém, cabe destacar, de acordo com Fleck (2010, p. 49), que a "história ensina que pode haver lutas árduas pelas definições de conceitos. Isso mostra como as convenções igualmente possíveis não são enxergadas como equivalentes, independentemente de quaisquer razões utilitaristas".

Dessa forma, podemos pensar a matemática como o espaço mais autônomo do campo científico, já que não se submete a nenhuma ingerência externa e nem às injunções do campo do poder e do campo econômico. "A autonomia não é um dado, mas uma conquista histórica, sempre renovada. Esquecemos isto facilmente no caso das ciências da natureza, porque a autonomia está inscrita" (BOURDIEU, 2001b, p. 70).

No entanto, "as ciências sociais têm de contar incessantemente com forças externa que travam de forma constante a 'descolagem"” (BOURDIEU, 2001b, p. 70). Desse modo, tanto a História quanto a Educação podem ser pensados como os lugares menos autônomos. Se a História ainda pode se afirmar pela sua antiguidade no campo científico, a Educação é uma das mais sujeitas às injunções políticas e econômicas de toda ordem, com pouca autonomia para definir seus objetos de estudo, seu âmbito e alcance de atuação. Portanto, podemos refletir, ao longo do texto, qual é o lugar ocupado pela História da Educação Matemática, a HEM? 
Pensando na transversalidade entre Bourdieu e Fleck, podemos pensar nas tensões e lutas simbólicas dentro do campo científico de Bourdieu, associado com a resistência dentro de um estilo de pensamento que leva a uma harmonia das ilusões na produção do conhecimento científico de Fleck (2010, p. 81):

A tendência à persistência dos sistemas de opinião nos mostra que, de certa maneira, devem ser considerados como unidades, como formações autônomas de estilo. Os sistemas não são apenas a soma de proposições parciais; enquanto totalidades harmoniosas, apresentam marcas específicas de estilo que determinam e condicionam cada uma das funções de conhecimento.

O caráter fechado dos sistemas, os efeitos recíprocos entre o conhecido, as coisas a serem conhecidas e os atores do conhecimento garantem a harmonia dentro do sistema, que é, ao mesmo tempo, uma harmonia das ilusões, que não se resolvem, de maneira alguma, dentro dos limites de um determinado estilo de pensamento.

Há uma relação dialética entre as estruturas e as estratégias dentro do campo científico, segundo Bourdieu (2013, p. 134),

A estrutura da distribuição do capital científico está na base das transformações do campo científico e se manifesta por intermédio das estratégias de conservação ou de subversão da estrutura que ela mesma produz. Por um lado, a posição que cada agente singular ocupa num dado momento na estrutura do campo científico é a resultante, objetivada nas instituições e incorporada nas disposições, do conjunto de estratégias anteriores desse agente e de seus concorrentes [...]. Por outro lado, as transformações da estrutura do campo são o produto de estratégias de conservação ou de subversão que têm seu princípio de orientação e eficácia nas propriedades da posição que ocupam aqueles que as produzem no interior da estrutura do campo.

A manutenção e a transformação da estrutura do campo científico dependem das estratégias dos agentes e de seus concorrentes, de acordo com Bourdieu. Dessa forma, aproximando com o pensamento de Fleck (2010, p. 88), o indivíduo pertence a vários coletivos de pensamento, assim, o pesquisador pertence a uma comunidade, "logo se transforma em seu membro e obedece às suas imposições", o que irá fortalecer o próprio coletivo de pensamento. 
Fazendo parte de uma comunidade, o estilo coletivo de pensamento passa por um fortalecimento social (cf. abaixo) comum a todas as formações sociais e submetido a um desenvolvimento através de gerações. Transforma-se em coação para os indivíduos, definindo "o que não pode ser pensado de outra maneira", fazendo com que épocas inteiras vivam sob a coerção de um determinado pensamento, queimando aqueles que pensam diferente, que não participam da atmosfera (Stimmung) coletiva (FLECK, 2010, p. 150, grifo do autor).

Assim, o estilo de pensamento de uma época, por exemplo, exerce coerção aos demais estilos de pensamento, associando a Bourdieu (2013, p. 137), "Os dominantes consagram-se às estratégias de conservação, visando assegurar a perpetuação da ordem científica estabelecida com a qual compactuam". Engloba a produção e a circulação da ciência oficial, seus bens científicos a fim de sua permanência e consagração por meio das instituições. Segundo Bourdieu (2001a), cada campo possui a institucionalização de um ponto de vista, de um habitus específico que é

[...] imposto aos novos postulantes como um direito de entrada, não é outra coisa senão um modo de pensamento específico (um eidos), princípio de uma construção específica da realidade, fundado numa crença pré-reflexiva no valor indiscutível dos instrumentos de construção e dos objetos assim construídos (um ethos) (BOURDIEU, 2001a, p. 121, grifos do autor).

No campo científico, tem-se o habitus científico, que se manifesta por meio das "práticas científicas é um sistema de disposições base, em grande parte inconscientes, transponíveis, que tendem a generalizar-se" (BOURDIEU, 2001b, p. 63). Podemos associar aos exames, às conferências, às palestras e aos seminários; e nos aspectos físicos, no tratamento com os pares, com uma postura, que é a "transcrição mais directamente visível, e a recepção social dada a esses sinais visíveis reenvia à pessoa em causa uma imagem de si mesma que faz com que se sinta ou não autorizada e encorajada nas suas disposições" (BOURDIEU, 2001b, p. 66).

Pensando nos conceitos cunhados por Fleck, podemos aproximar o habitus científico de Bourdieu com o conceito de circulação intracoletiva de pensamento. De acordo com Fleck (2010), os indivíduos se posicionam de maneira específica dentro da circulação intracoletiva, há uma subordinação, dependência, confiança 
e solidariedade. "Todo tráfego de pensamento intracoletivo (intrakollektiven Denkverkehr), portanto, é dominado por um sentimento específico de dependência" (FLECK, 2010, p. 158), que leva ao fortalecimento do estilo de pensamento compartilhado pelo coletivo. Assim, "a confiança nos iniciados, a dependência por parte destes da opinião pública, a solidariedade intelectual dos pares, que estão a serviço da mesma ideia, são forças sociais alinhadas que criam uma atmosfera comum específica" (FLECK, 2010, p. 158).

Ou seja, a circulação intracoletiva ocorre no interior do coletivo de pensamento, no qual o sujeito aprende e compartilha os conhecimentos e práticas do estilo de pensamento vigente naquele coletivo, assegurando a extensão do estilo de pensamento. No entanto, é importante ressaltar que

Em um determinado estágio do desenvolvimento, os hábitos de pensamento e as normas são vistos como óbvios, como sendo os únicos possíveis, como aquilo que não é passível de reflexões ulteriores. No entanto, uma vez tornados conscientes, também podem ser considerados como sobrenaturais, como dogmas, como sistema de axiomas ou convenção útil (FLECK, 2010, p. 158-159).

Dessa maneira, aproximando o pensamento de Fleck ao de Bourdieu, em relação à coerção, à dependência e às disposições dentro do campo científico, podemos mencionar o termo illusio. Segundo Bourdieu (2001b, p. 102) os "requisitos de admissão tácitos associados à illusio comum que condiciona a pertença ao campo científico está implicada a aceitação do estado das normas acerca da validade de um facto científico e, mais exactamente, o reconhecimento". O agente "joga o jogo", ou seja, se submete "na experiência colectiva, regulada por normas de comunicação e argumentação" (BOURDIEU, 2001b, p. 102).

Repensando em todos os termos e as aproximações, ou melhor, nas transversalidades entre Bourdieu e Fleck, como podemos caracterizar um campo científico? Em particular, a HEM, quais são seus elementos constitutivos? Primeiro não pretendemos esgotar essa reflexão, assim como não pretendemos afirmar que a HEM é ou não um campo científico. Porém, cabe destacar algumas ações para pensar o seu lugar de constituição e busca de representação.

Segundo Brito e Miorim (2016), a primeira dissertação na área da HEM foi em 1984, de Maria Antonieta Meneghini Martins, intitulada Estudo da Evolução do Ensino secundário no Brasil e no estado do Paraná com ênfase na disciplina de Matemática, pela Universidade Federal do Paraná (UFPR), mestrado em Educação. O primeiro doutorado foi defendido em 1995, de Maria 
Ângela Miorim, intitulado O ensino de matemática: evolução e modernização, na área da Educação, pela Universidade Estadual de Campinas (UNICAMP).

Até o final da década de 1990, essa produção [no âmbito da HEM] pode ser caracterizada pela irregularidade de frequência, que se torna nula, em alguns anos. A partir de 1996 e 2002, temos, respectivamente, a produção de dissertações e teses em todos os anos. [...] O período de 2003 a 2011 se caracteriza por uma produção regular, com tendência crescente, que se consolida a partir de 2007, com uma quantidade maior ou igual a dez trabalhos defendidos em todos os anos (BRITO; MIORIM, 2016, p. 78-79).

O aumento de produções científicas na área, de acordo com as autoras Brito e Miorim (2016), está relacionado à criação de diversos grupos de pesquisa, no âmbito nacional, que investigam a HEM. Em um levantamento recente no Diretório dos Grupos de Pesquisa no Brasil, vinculado ao Conselho Nacional de Desenvolvimento Científico e Tecnológico (CNPq), obteve-se 18 resultados de Grupos de pesquisa, associados a diversas instituições de Ensino Superior. A busca foi realizada por meio do descritor "história da educação matemáti$c a$ ", aplicado aos campos nome do grupo e linha de pesquisa o termo exato (DGP/CNPq, 2019).

Além da produção de teses, dissertações e da criação dos grupos de pesquisas, podemos destacar os eventos na área da HEM, que são importantes no processo de socialização e divulgação das pesquisas. Destacamos dois eventos bienais, o primeiro é o Congresso Ibero-Americano de História da Educação Matemática (CIHEM) que, em 2019, está na sua quinta realização na cidade de Bogotá, Colômbia. E a criação do Encontro Nacional de História da Educação Matemática (ENAPHEM) que, no ano de 2018, teve sua quarta edição, na cidade de Campo Grande no estado do Mato Grosso do Sul (MS). Assim como os eventos, as revistas também realizam um papel importante na divulgação do conhecimento científico, na HEM, a saber, a HISTEMAT - Revista de História da Educação Matemática, órgão da Sociedade Brasileira de História da Matemática, e o International Journal for the History of Mathematics Education que circulou entre 2006 e 2016 (VALENTE, 2017).

Cabe destacar, segundo Fleck (2010, p. 154), que ao constituir um grupo fixo, "não cabe ao conceito de coletivo de pensamento, da maneira que o estamos empregando, a saber, como meio de análise do condicionamento social do pensamento". Do mesmo modo, para Bourdieu (2004, p. 18), que não "basta reunir um grupo para produzir a reflexão científica, mas acredito que, com a 
condição de instaurar uma tal estrutura de troca que traga em si mesma o princípio de sua própria regulação".

Dessa maneira, pensando na troca de ideias, práticas e teorias, nota-se uma mobilização para a criação de disciplinas, neste caso, a HEM. Segundo Brito e Miorim (2016), a disciplina de História da Educação Matemática foi inserida no curso de licenciatura em Matemática pela primeira vez na Universidade Federal do Rio Grande do Norte (UFRN), no ano de 2001. Há mais quatro universidades que nos últimos dez anos inseriram a HEM como disciplina no curso de licenciatura em Matemática: o Instituto Federal do Rio Grande do Norte (IFRN); Universidade Federal de Goiás (UFG); Universidade Federal do Mato Grosso (UFMT); e a Universidade Estadual Paulista "Júlio de Mesquita Filho" (UNESP).

Outras mobilizações vêm ocorrendo na Universidade Federal de Juiz de Fora (UFJF) a partir de 2009 (OLIVEIRA, 2017). No ano de 2017, ocorreu a primeira oferta da disciplina na Universidade Federal do Rio Grande do Sul (UFRGS), de caráter obrigatório para os alunos ingressantes (BÚRIGO et al., 2017); e na Universidade Federal de Santa Catarina (UFSC), como optativa aos alunos matriculados no sétimo semestre do curso de licenciatura em Matemática (COSTA, 2017).

A institucionalização de um saber em uma disciplina leva consigo ideias, métodos e práticas a partir de um ponto de vista. Pensando nas mobilizações que estão acontecendo, destacamos a fala de Valente (2016, p. 13), ao mencionar o lugar da HEM

Na perspectiva de ser transformada em disciplina acadêmico-científica, a história da educação matemática passa a ser considerada como conhecimento, no âmbito da Educação Matemática, enquanto campo científico, e vem a ser tratada como uma dimensão importante para compreender e encaminhar orientações às demandas da educação matemática em todos os níveis de ensino.

Uma das preocupações de Valente (2016, p. 14), é a originalidade dos conteúdos, a elaboração de problemas próprios da HEM: "Há que ser realizado o esforço da construção teórica de problemáticas não presentes em outras áreas".

A disciplina, para Bourdieu (2001b, p. 92), "é um campo relativamente estável e delimitado", socialmente reconhecido e inscrito "em instituições, laboratórios, departamentos universitários, revistas, instâncias nacionais e internacionais (congressos), processos de certificação de competências, sistemas de retribuição, prêmios" (BOURDIEU, 2001b, p. 92). Do mesmo modo, 
Fleck (2010, p. 85), ao tratar do universo científico, do seu lado formal, de sua estrutura social, considera que é "um trabalho coletivo organizado com divisão de trabalho, colaboração, trabalhos preparativos, assistência técnica, troca de ideias, polêmicas etc.". No entanto, existe uma hierarquia, "grupos, adeptos e adversários, sociedades e congressos, periódicos, instituições de intercâmbio etc. O portador do saber é um coletivo bem organizado, que supera de longe a capacidade de um indivíduo" (FLECK, 2010, p. 85).

O papel das instituições formadoras - como a escola, as disciplinas, os grupos de pesquisas, os coletivos de pensamento - é ocultar a relação de forças que define a cultura de um grupo como cultura legítima, contribuindo para a reprodução da estrutura de classe, da dominação e da exploração de uma classe sobre a outra. Em relação à resistência dentro do campo científico, Fleck (2010, p. 144) menciona que "o trabalho do pesquisador consiste em diferenciar, no meio da confusão incompreensível, no caos que enfrenta, entre aquilo que obedece à sua vontade e aquilo que resulta de si mesmo e que resiste à sua vontade".

\section{Algumas considerações}

Colocar em diálogo autores de contextos históricos e sociais distintos é um desafio, mas é importante fazê-lo para avançarmos na produção do conhecimento científico. Neste artigo buscamos aproximar a teoria epistemológica de Ludwik Fleck e a sociologia de Pierre Bourdieu.

Mobilizamos conceitos importantes para os autores, como estilo de pensamento e coletivo de pensamento para Fleck; e campo científico e habitus para Bourdieu. Buscamos ser vigilantes e não migrar ideias, conceitos, sem caracterizá-los. Utilizamos como locus a História da educação matemática (HEM) para mostrar os elementos constitutivos de um campo científico.

Os aspectos relacionados às tensões e às lutas simbólicas do campo científico são abordados por Bourdieu. Vale ressaltar que é um processo sempre presente, ininterrupto, não finalizado, suscetível a movimentos no exterior e interior do campo. No entanto, Fleck aborda o caráter coercitivo do estilo de pensamento, mas que ao mesmo tempo é o que irá fortalecer o coletivo de pensamento por meio da circulação intracoletiva de ideias, práticas e teorias.

Mesmo os autores sendo de épocas, contextos e áreas de formação diferentes, há muito em comum quando se trata da produção do conhecimento científico. Foi possível realizar uma transversalidade, no sentido de que os autores se cruzam por determinados conceitos, principalmente aos aspectos 
relacionados ao conhecimento científico, como algo social e não isolado, que faça parte de um coletivo.

Contudo, pensar a HEM como um campo científico ainda é prematuro, dado que o campo científico busca uma autoridade, um reconhecimento e uma autonomia científica. Cabe neste momento investigar o lugar da HEM e realizar os seguintes questionamentos: quais são os agentes que investigam a HEM? A partir de quais referenciais teóricos e metodológicos esse lugar vai se caracterizando? Quais estratégias para legitimação de espaços podemos observar, no âmbito do Brasil? Só assim poderemos observar sua produção, seu(s) estilo(s) de pensamento, sua representação, por meio das instituições, e legitimação.

\section{REFERÊNCIAS}

BOURDIEU, P. O campo científico. In: ORTIZ, R. (Org.). A sociologia de Pierre Bourdieu. São Paulo: Olho D’Água, 2013. p. 122-155.

. Os usos sociais da ciência: por uma sociologia clínica do campo científico. São Paulo: Unesp, 2004.

. Meditações pascalianas. Rio de Janeiro: Bertrand Brasil, 2001a.

. Para uma sociologia da ciência. Lisboa: Ed. 70, $2001 \mathrm{~b}$.

. Introdução a uma sociologia reflexiva. In: BOURDIEU, P. O poder simbólico.

Rio de Janeiro: Bertrand Brasil; Lisboa: Difel, 1989. p. 17-58.

; CHAMBOREDON, J. C.; PASSERON, J. A Profissão de sociólogo: preliminares epistemológicas. Petrópolis: Vozes, 1999.

BRITO, A. J.; MIORIM, M. A. A institucionalização da História da Educação Matemática. In: GARNICA, A. V. M. (Org.). Pesquisa em História da Educação Matemática no Brasil: sob o signo da pluralidade. 1. ed. São Paulo: Livraria da Física Editora, 2016. V. 1, p. 67-92.

BÚRIGO, E. Z.; DALCIN, A.; FISCHER, M. C. B. História da Educação Matemática: a institucionalização do campo em um curso de licenciatura. Cadernos de História da Educação (online), v. 16, p. 619-639, 2017.

CONSELHO NACIONAL DE DESENVOLVIMENTO CIENTÍFICO E TECNOLÓGICO (CNPq). Diretório de Grupos de Pesquisa. 2019. Disponível em: http://lattes.cnpq. br/web/dgp. Acesso em: 7 jul. 2019. 
DELIZOICOV, D.; CASTILHO, N.; CUTOLO, L. R. A.; DA ROS, M. A.; LIMA, A. Sociogênese do conhecimento e pesquisa em ensino: contribuições a partir do referencial Fleckiano. Caderno Brasileiro de Ensino de Física, Florianópolis, p. 52-69, jan. 2002.

FLECK, L. Gênese e desenvolvimento de um fato cientifico: introdução à doutrina do estilo de pensamento e do coletivo de pensamento. Belo Horizonte: Fabrefactum Editora, 2010.

OLIVEIRA, M. C. A. História da educação matemática como disciplina na formação de professores que ensinam Matemática. Cadernos de História da Educação (online), v. 16, p. 653-665, 2017.

SCHÄFER, L.; SCHNELLE, T. Introdução. In: FLECK, L. Gênese e Desenvolvimento de um Fato Científico: introdução à doutrina do estilo de pensamento e do coletivo de pensamento. Belo Horizonte, Fabrefactum Editora. 2010.

VALENTE, W. R. A internacionalização da pesquisa em História da Educação Matemática: movimentos de criação de um novo campo disciplinar. Cadernos de História da Educação (online), v. 16, p. 610-618, 2017.

. O movimento da história da educação matemática. In: GARNICA, A. V. M. (Org.). Pesquisa em História da Educação Matemática no Brasil: sob o signo da pluralidade. 1. ed. São Paulo: Livraria e Editora da Física, 2016. V. 1, p. 11-18.

Texto recebido em 02/07/2019.

Texto aprovado em 15/10/2019. 